\title{
The Contribution of Scientific Popularization Video to Environmental Protection
}

\author{
Si Chen \\ Shenzhen Experimental School Senior High School, Shenzhen 518000, China. \\ wpikaqiu@163.com
}

Keywords: Mangrove Swamp, Science Popularization, Environmental Protection.

\begin{abstract}
A relatively small amount of data have been conducted to investigate the effectiveness of science popularization on environmental education. This paper studied the association of popularizing science through video with the resulting effectiveness of environmental protection. We made a video about mangrove swamp and conducted a questionnaire with the same content twiceonce before the participants watch the video and once after. In total, 181 valid questionnaire data from random WeChat online users in Shenzhen, China were collected. Then, we compared the results of the two questionnaires and analysed the data obtained, which revealed that after watching the video, audience managed to learn more about not only the characters of the mangrove swamp, but also its importance to ecological environment, and hence they developed a greater concern toward mangrove swamp, becoming more willing to actively protect the environment. To conclude, science popularization about environment can help protect the environment.
\end{abstract}

\section{Introduction}

Environment is the essence of human development. However, because of human's improper utilization of the environment, some pollution and ecology destruction have been resulted. When pollution exceeds the environment's self-mending ability, the natural environment is severely polluted and damaged, intimidating human's living condition [1]. In recent years, global temperature increases; extreme weathers like drought, flood, and hurricane occurs with higher frequency; large numbers of death, large scale of damage are brought to population; and human's daily life are greatly affected through habitat destruction, living condition alternation, population migration, water source pollution, food deficiency as well as many other unfavorable events. The air pollution is worsening; food security problem is deteriorating; and the burden of public hygiene is becoming heavier than ever. All these above are the negative impacts led by the deteriorating environment to humanity [2]. As a result, protecting the environment has become an inevitable and crucial issue for the whole world to work out [3].

Recently, a variety of ways to protect the environment has been explored, and many of them are in high demand of social resources. In an attempt to find a way that is both cost-efficient and effective, we came up with one method satisfying the two requirements above — popularizing environmental science through video. We designed an experiment to test its efficiency, hoping it can inspire more people to develop this aspect of study further and take more action in environmental protection.

Our study aimed to investigate the improvement of people's knowledge and awareness of mangrove swamp protection after watching a video introducing unique and basic characters of mangroves and the value of mangrove swamps in various aspects. We carried out our investigation in the form of questionnaire in Shenzhen Mangrove Swamp Reserve in China. 


\section{Methods}

We used questionnaire to test participants' knowledge of the mangrove swamp and their extent of concern to this specific ecology system. We made a video about some basic knowledge of mangrove swamp and introduced its importance to both the ecologic environment and human life. Then we designed a questionnaire based on the content presented in the video. The questionnaire together with the video was latterly delivered online to users of WeChat, which is the most popular social media in China, randomly in Shenzhen Mangrove Swamp Reserve with instructions in it. In total,181 people took part in the experiment. Each participant completed this questionnaire twice, once before watching the video and another after. The data resulted were collected and compared, which showed that watching science popularization video of mangrove swamp is capable of evoking people's awareness of protecting mangrove swamp and improving their sense of responsibility of environmental protection.

The questionnaire used in the experiment is shown in Table1.

Table 1 Three Scheme comparing

\begin{tabular}{|c|}
\hline 1. Which of the followings are three main characters of mangrove? \\
\hline A. viviparous \\
\hline B. aerial root \\
\hline C. salt secretion \\
\hline D. asexual reproduction \\
\hline $\begin{array}{l}\text { 2. There is a kind of rare migrant bird fly to the mangrove swamp in Shenzhen to winter each } \\
\text { year. What is the name of the bird? }\end{array}$ \\
\hline A. Platalea minor \\
\hline B. Ibidorhyncha struthersii \\
\hline C. Sturnus vulgaris \\
\hline D. Indicator xanthonotus (Yellow-rumped) \\
\hline 3. Which of the followings are values or ecological benefits provided by mangrove swamp? \\
\hline A. Pharmacology \\
\hline B. Beach protection and accretion promotion \\
\hline C. An important source of timber \\
\hline D. Balance the $\mathrm{pH}$ of water \\
\hline 4. Which of the following picture depicts mangrove swamp? \\
\hline A. picture1 \\
\hline B. picture2 \\
\hline C. picture3 \\
\hline D. picture4 \\
\hline 5. Mangrove mainly grow in which of the following places? \\
\hline A. Around beaches \\
\hline B. Coastal saline or brackish water \\
\hline C. Hardened soil \\
\hline D. Euphotic zone \\
\hline 6. What altitude should we hold toward mangrove swamp? \\
\hline A. No interference. Let it grow naturally. \\
\hline B. Cut down mangroves and convert the swamp into aquafarm and farmland to earn profit \\
\hline $\begin{array}{l}\text { C. Actively protect and appropriately exploit mangrove swamp. Realize the harmony } \\
\text { development of both human and mangrove swamp. }\end{array}$ \\
\hline D. Completely transform into tourist attraction. \\
\hline
\end{tabular}




\section{Results}

\subsection{Data Collection.}

The questionnaire included 6 questions and were randomly delivered online to WeChat users in Shenzhen. At the end of the experiment, 181 valid pairs of questionnaires were collected. After data processing, the result is shown in Figure 1.

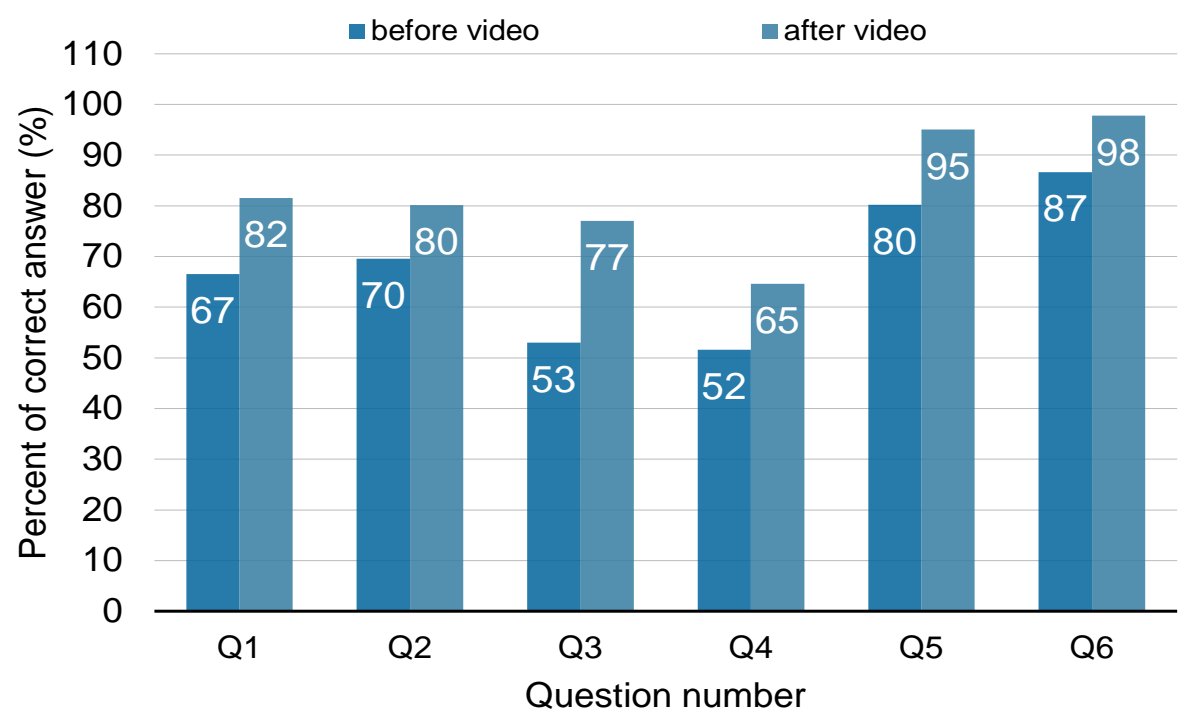

Figure 1 The outcome of data processing

Among the 181 people who finished both questionnaires, 66.5 percent of them answered the first question correctly, while after watching the video, the percentage of correctness rose to 81.5. For the second question, there were 69.59 percent of the participants who answered correctly before watching the video and the percentage increased to 80.11 after the video. For the third question, the percentage of correctness rose from 53 to 77 . For the fourth question, 51.61 percent of the people filled in the questionnaire with the right answer before the video and after the video the number rose to 64.64. For the fifth question, the percentage of correctness steadily increased from 80.18 to 95.03 . For the last question of the questionnaire, the video helped 11.15 percent more people to get the right answer, from 86.64 percent to 97.79 percent.

\subsection{Data Analysis.}

Based on the statistic results presented above, the following analysis was carried out. The first question tested the people's basic knowledge of mangrove swamps. Through learning more about mangrove swamps' characters and knowing their unique abilities, citizens' sense of environmental protection has be improved.

The second question investigated citizens' basic knowledge of rare species especially birds living in mangrove swamps. Mangrove swamps are one of the environments with the greatest biodiversity, and one of the best habitats for rare birds, so showing that mangrove swamps are the substantial basis of the survival of so many precious wildlives urged people to become aware of the value of mangrove swamps and thus the necessity of protecting it.

The third question investigated the ecological benefits brought by mangrove swamps. In this question, we set up a confusing choice that seemed reasonable to participants, successfully evoking people's curiosity to find out the truth and hence improving their knowledge of further details of the importance of mangrove swamps. Though searching for the correct answer in various ways, video included, participants realized mangrove swamps' indispensable value to the ecology system, more profoundly stimulating the formation of peoples' awareness of environmental protection.

The fourth question was about the recognition of mangroves. After knowing what do mangrove swamps look like, citizens became able to identify this valuable type of environment and contribute more to the protection and science popularization. 
The fifth question tested another basic knowledge of mangroves - their habitat. The data collected managed to reveal that the video helped enhance people's general knowledge of this special environment and learn about their significance to the ecology system.

The last question tested the proper method of exploiting as well as maintaining mangrove swamps. Because of the science popularization, citizens basically formed the right attitude toward mangrove swamp protection.

\section{Conclusion}

In conclusion, towards citizens in Shenzhen, China, science popularization video contributes to environmental protection.

We defined the weight of questions with multiple correct answers as 0.25 and the weight of questions with single correct answer as 0.125 . Then, multiplying the percentage of correctness of each question with its weight, we derived a result that the overall percentage of correctness rose from 65.8775 to 81.82125 after watching the science popularization video.

From the results above, we justified the importance of popularizing science of environment and ecology to environmental protection. This is because people will steadily take action only when they know how the environment is closely related to their living condition and its value to the entire world. The science popularization video does help people to learn about mangrove swamps more thoroughly and more systematically, hence contributing to the environmental protection.

Finding an economy-efficient way to protect the environment is an essential issue in today's increasingly crucial society, as currently money spent to solve environmental problems overweighs the profits produced by the development of industry and economy. And we believe that promoting public science popularization of environment related knowledge is a promising path, which has been proven by part in our study. However, there still exists some limitations in our investigation, for we have not investigated the relationship between the cost of science popularization and its effectiveness of environmental protection is one of them, due to the difficulty of measuring the cost produced by making large scales of public science popularization applications. Another limitation is that our investigation is largely based on questionnaire and cannot conduct following study on whether those participants will actually take part in the protection activities if there is a chance.

\section{References}

[1]. The damage caused by environmental pollution to human health. www.qikanwang.net. article number: 1674-6708 (2012) 73-0100-02

[2]. Anonymity. The environmental impact toward humanity. www.docin.com

[3]. Xingna Qi. Discuss the importance of environmental protection. Engineering technology: quotation version, 2016 (6): 00073-00074 